\title{
Effect of the Electrode Type on the Dielectric and Piezoelectric Properties of Piezoelectric PMN-PZT Single Crystals
}

\author{
Jong-Yeb Lee*, Hyun-Taek Oh*, Kyoon Choi**, and Ho-Yong Lee ${ }^{* * *{ }^{\dagger}}$ \\ *R \& D Center, Ceracomp Co., Ltd., Chungnam 331-979, South Korea \\ **Icheon Brach, Korea Institute of Ceramic Engineering \& Technology, Gyeonggi-do 467-843, South Korea \\ ***Department of Materials Science and Engineering, Sunmoon University, Chungnam 336-708, South Korea \\ (Received November 19, 2014; Revised December 10, 2014; Accepted December 15, 2014)
}

\section{압전 PMN-PZT 단결정의 유전 및 압전 특성에 미치는 전극 종류의 영향}

\author{
이종엽*·오현택*·최 균**·이호용***,† \\ *(주)세라콤 연구개발부 \\ **한국세라믹기술원 이천분원 \\ ***선문대학교 신소재공학과 \\ (2014년 11월 19일 접수;2014년 12월 10일 수정 ; 2014년 12월 15일 채택)
}

\begin{abstract}
The effect of the electrode type on the dielectric and piezoelectric properties of $\mathrm{Pb}\left(\mathrm{Mg}_{1 / 3} \mathrm{Nb}_{2 / 3}\right) \mathrm{O}_{3}-\mathrm{PbZrO}_{3}-\mathrm{PbTiO} \mathrm{O}_{3}(\mathrm{PMN}-\mathrm{PZT})$ single crystals was investigated in an effort to improve their properties for various piezoelectric applications. First, three different types of PMN-PZT single crystals [PMN-PZT-A (piezoelectrically soft type; dielectric constant $~ 10,000$ ), PMN-PZT-B (piezoelectrically soft type; phase-transition temperature between the rhombohedral and tetragonal phases $\left.\left(\mathrm{T}_{\mathrm{RT}}\right) \sim 145^{\circ} \mathrm{C}\right)$, PMN-PZT-C (piezoelectrically hard type; high mechanical quality factor $\left.\left.\left(\mathrm{Q}_{\mathrm{m}}\right) \sim 1,000\right)\right]$ were fabricated using the solid-state single crystal growth (SSCG) method. Then, four different types of electrodes [sputtered $\mathrm{Au}$, sputtered $\mathrm{Cr} / \mathrm{Au}$, sputtered $\mathrm{Ti} / \mathrm{Au}$, and fired $\mathrm{Ag}$ ] were formed on the single crystals, and their dielectric and piezoelectric properties were measured. The single crystals with a sputtered Ti/Au electrode showed the highest dielectric and piezoelectric constants but the lowest coercive electric field $\left(\mathrm{E}_{\mathrm{C}}\right)$. The single crystals with a fired $\mathrm{Ag}$ electrode showed the lowest dielectric and piezoelectric constants but the highest coercive electric field $\left(\mathrm{E}_{\mathrm{C}}\right)$. This dependence on the type of electrode was most significant in the piezoelectrically hard PMN-PZT-C single crystals. However, the effects of the electrode type on the phase transition temperatures $\left(T_{C}, T_{R T}\right)$ and dielectric loss were negligible. These results clearly demonstrate that it is important to select an appropriate electrode so as to maximize the dielectric and piezoelectric properties of single crystals in each type of piezoelectric application.
\end{abstract}

Key words : Electrode, PMN-PZT, Single crystals, Piezoelectric, Dielectric

\section{1. 서 론}

1950 년대에 $\mathrm{PZT}\left[\mathrm{Pb}(\mathrm{Zr}, \mathrm{Ti}) \mathrm{O}_{3}\right]$ 세라믹스가 개발된 후, 현재까지 70년 동안 $\mathrm{PZT}$ 세라믹스가 압전 재료로서 가 장 널리 사용되었다. ${ }^{1)}$ 그러나 1980 년대에 일본 동경공 대 Kuwata 교수 그룹과 1990 년대 미국 펜실베이니아 주립 대학 Tom Shrout 교수 그룹에서 PZN-PT $\left[\mathrm{Pb}\left(\mathrm{Zn}_{2 / 3} \mathrm{Nb}_{1 / 3}\right) \mathrm{O}_{3}\right.$ $\left.\mathrm{PbTiO}_{3}\right]$ 와 $\mathrm{PMN}-\mathrm{PT}\left[\mathrm{Pb}\left(\mathrm{Mg}_{2 / 3} \mathrm{Nb}_{1 / 3}\right) \mathrm{O}_{3}-\mathrm{PbTiO}_{3}\right]$ 단결정들이 개발되면서 압전 재료 시장에 큰 변화를 가져 왔다. ${ }^{2-4)}$ Table 1에서 PZT 다결정체 세라믹스와 PMN-PT 단결정

\footnotetext{
${ }^{\dagger}$ Corresponding author : Ho-Yong Lee

E-mail : hlee@sunmoon.ac.kr

Tel : +82-41-530-2366 Fax : +82-41-584-2367
}

의 특성을 비교하였다. PZN-PT와 PMN-PT 단결정들은 $\mathrm{PZT}$ 다결정체 세라믹스에 비하여 압전 상수 $\left(\mathrm{d}_{33}>2,000\right.$ $\mathrm{pC} / \mathrm{N})$ 와 전기기계결합계수 $\left(\mathrm{k}_{33}>0.9\right)$ 에서 급격한 증가를 보였다. 그리고 $\mathrm{d}_{31}$ 과 $\mathrm{k}_{31}$ 을 비교하면, PMN-PT 단결정이 $\mathrm{PZT}$ 세라믹스에 비하여 $\mathrm{d}_{31}$ 과 $\mathrm{k}_{31}$ 은 각각 8 배와 2 배 정 도가 더 높았다. 그리고 Table 2에서 보는 것과 같이, 압 전 다결정체 세라믹스와는 달리 압전 단결정은 결정 방 향에 따라서 압전 특성이 크게 변하여 특정 결정면과 방 향에서는 PZT 세라믹스에서는 기대할 수 없었던 아주 큰 압전 상수를 얻을 수도 있었다. ${ }^{2-4)}$

PMN-PT 압전 단결정은 미국의 ONR (Office of Naval Research)과 DARPA (Defense Advanced Research Projects Agency) 주도하에 주로 해군의 SONAR용 트랜스듀서에 
Table 1. Piezoelectric Properties of PZT-5H Ceramics and PMN-PT Single Crystals

\begin{tabular}{ccccc}
\hline & $\mathrm{d}_{33}[\mathrm{pC} / \mathrm{N}]\left(\mathrm{k}_{33}\right)$ & $\mathrm{d}_{31} / \mathrm{d}_{32}\left(\mathrm{k}_{33} / \mathrm{k}_{32}\right)$ & $\mathrm{d}_{15}\left(\mathrm{k}_{15}\right)$ & $\mathrm{d}_{36}\left(\mathrm{k}_{36}\right)$ \\
\hline PMN-PT Single crystals & $1,500 \sim 2,500\left(\mathrm{k}_{33}>0.9\right)$ & $1,000 \sim 2,000\left(\mathrm{k}_{31}>0.85\right)$ & $4,000 \sim 6,000\left(\mathrm{k}_{15}>0.95\right)$ & $2,000 \sim 2,500\left(\mathrm{k}_{36}>0.9\right)$ \\
\cline { 2 - 5 } PZT-5H Ceramics & $600\left(\mathrm{k}_{33} \sim 0.75\right)$ & $-250\left(\mathrm{k}_{31} \sim 0.4\right)$ & $750\left(\mathrm{k}_{15} \sim 0.7\right)$ & 0 \\
\hline
\end{tabular}

Table 2. Piezoelectric Properties of PMN-PT Single Crystals at Different Crystallographic Orientations

\begin{tabular}{ccccc}
\hline & $\mathrm{d}_{33}[\mathrm{pC} / \mathrm{N}]\left(\mathrm{k}_{33}\right)$ & $\mathrm{d}_{31} / \mathrm{d}_{32}\left(\mathrm{k}_{33} / \mathrm{k}_{32}\right)$ & $\mathrm{d}_{15}\left(\mathrm{k}_{15}\right)$ & $\mathrm{d}_{36}\left(\mathrm{k}_{36}\right)$ \\
\hline$<001>$ Poling & $1,500 \sim 2,500\left(\mathrm{k}_{33}>0.9\right)$ & $-800 \sim-1,000$ & $<100$ & 0 \\
\cline { 2 - 5 }$<011>$ Poling & $<1,000$ & $1,200 \sim 2,000\left(\mathrm{k}_{32}>0.85\right)$ & $2,000 \sim 3,000\left(\mathrm{k}_{15}>0.9\right)$ & $2,000 \sim 2,500\left(\mathrm{k}_{36}>0.9\right)$ \\
\cline { 2 - 6 } & $<111>$ Poling & $\sim-150$ & $4,000 \sim 6,000\left(\mathrm{k}_{15}>0.95\right)$ & 0 \\
\hline
\end{tabular}

활용하기 위하여 개발되었다. 미국 NUWC와 PSU ARL 등에서는 기존의 PZT 세라믹스 트랜스듀서보다 성능이 우수하고 크기도 $1 / 2$ 로 소형화된 압전 단결정 SONAR용 트랜스듀서를 이미 개발하여 시스템 적용 및 실용화를 준 비하고 있다. 민간 분야에서는 Philips와 휴먼스캔 등에서 압전 단결정들을 의료용 초음파 진단기 및 치료기에 사 용하기 위해서 개발하였으며, 현재 Philips, 휴먼스캔, GE, Siemens와 Hitachi 등에 의해서 압전 단결정 초음파 진단 기가 상용화되었다. SONAR용 트랜스듀서와 의료용 초음 파 진단기를 시작으로, 압전 액추에이터, 압전 센서, 의료 용 초음파 치료기(HIFU), 초음파 모터와 압전 에너지 수 확기 등의 다양한 분야에 응용이 시도되고 있다. ${ }^{2-4)}$

최근의 연구에서 PMN-PT 압전 단결정의 유전 및 압전 특성이 전극의 종류에 따라서 변한다는 것이 보고되었다. ${ }^{5)}$ 이러한 전극의 효과를 이해하기 위해서, 본 연구에서는 PMN-PZT-A (소프트 계열; 유전 상수 10,000), PMN-PZT$\mathrm{B}$ (소프트 계열; 상전이 온도 $\left(\mathrm{T}_{\mathrm{RT}}\right) \sim 145^{\circ} \mathrm{C}$ )와 $\mathrm{PMN}-\mathrm{PZT}$ $\mathrm{C}$ (하드 계열; 기계적 품질 계수 $\left.\left(\mathrm{Q}_{\mathrm{m}}\right) 1,000\right)$ )의 세 종류의 $\mathrm{PMN}-\mathrm{PZT}$ 단결정들을 고상 단결정 성장법을 이용하여 제 조하였다. 그리고 각 단결정들 표면에 진공 증착된 $\mathrm{Au}$ (Sputtered $\mathrm{Au}$ ), 진공 증착된 $\mathrm{Cr} / \mathrm{Au}$ (Sputtered $\mathrm{Cr} / \mathrm{Au}$ ), 진 공 증착된 $\mathrm{Ti} / \mathrm{Au}$ (Sputtered $\mathrm{Ti} / \mathrm{Au}$ )와 스크린 프린팅된 $\mathrm{Ag}$ (Fired $\mathrm{Ag}$ )의 전극을 형성하고, 세 종류의 PMN-PZT 단결 정들의 유전 및 압전 특성을 각각 측정하였다. 세 종류의 PMN-PZT 단결정들에서 유전 상수 $\left(\mathrm{K}_{3}{ }^{\mathrm{T}}\right)$, 유전 손실 $(\tan \delta)$, 상전이 온도들 $\left(\mathrm{T}_{\mathrm{C}}\right.$ 와 $\left.\mathrm{T}_{\mathrm{RT}}\right)$, 항전계 $\left(\mathrm{E}_{\mathrm{C}}\right)$ 와 잔류 분극 등과 같은 유전 및 압전 특성에 미치는 전극의 효과를 연구하 였다. 그리고 본 연구를 통하여, 압전 단결정의 종류와 응 용 분야에 따라서 적합한 종류의 전극을 사용하는 것이 필수적임을 보였다.

\section{2. 실험 방법}

본 연구에서 사용된 세 종류의 PMN-PZT 압전 단결정 들[PMN-PZT-A(소프트 계열; 유전 상수 10,000), PMN$\mathrm{PZT}-\mathrm{B}$ (소프트 계열; 상전이 온도 $\left(\mathrm{T}_{\mathrm{RT}}\right) \sim 145^{\circ} \mathrm{C}$ )와 $\mathrm{PMN}-$
PZT-C(하드 계열; 기계적 품질 계수 $\left.\left.\left(\mathrm{Q}_{\mathrm{m}}\right) \sim 1,000\right)\right]$ 은 고상 단결정 성장법(solid-state single crystal growth (SSCG) method)을 이용하여, ${ }^{6-9)}$ (주)세라콤(www.ceracomp.com)에서 제조되었다. $\mathrm{Pb}_{3} \mathrm{O}_{4}(99.9 \%$, Alfa Aesar, Ward Hill, MA), $\mathrm{MgNb}_{2} \mathrm{O}_{6}(99.9 \%$, H. C. Starck $\mathrm{GmbH}$, Newton, MA)와 $\mathrm{TiO}_{2}$ (99.99\%, Ishihara, San Francisco, CA)가 원료 분말 로 사용되었다. 각 원료 분말들을 정량한 다음, 볼 밀링 공정을 이용하여 24 시간 동안 혼합하였고, 건조 후에 800 도에서 하소하였다. 하소된 분말들은 과량의 $\mathrm{PbO}$ 분말과 같이 2차 볼 밀링 하였고, 건조 후에 일축 가압 성형하고 소결하였다. 1차 소결 후에 $\mathrm{Ba}\left(\mathrm{Zr}_{0.1} \mathrm{Ti}_{0.9}\right) \mathrm{O}_{3}$ 종자 단결정을 PMN-PZT 소결체 위에 두고, 고상 단결정 성장을 위한 열 처리를 하였다. 고상 단결정 성장을 위한 열처리는 휘발성 이 강한 $\mathrm{PbO}$ 의 손실을 막기 위해서 이중 도가니(double crucible)내에서 실시하였다. 단결정 성장 열처리 공정 중에 $\mathrm{Ba}\left(\mathrm{Zr}_{0.1} \mathrm{Ti}_{0.9}\right) \mathrm{O}_{3}$ 종자 단결정은 PMN-PZT 다결정체 안으로 연속적으로 성장하였고, 결과적으로 $15 \times 15 \times 5 \mathrm{~mm}^{3}$ 크기 의 PMN-PZT 단결정이 제조되었다. 고상 단결정 성장법에 서는 단결정 제조 공정 중에 PMN-PZT 상의 용융(melting) 이 일어나지 않았기 때문에, 제조된 단결정 내에 조성 구 배가 관찰되지 않았으며 화학적으로 균일하였다.

제조된 단결정은 $(001)$ 면으로 절단하였고, 각 단결정 들 표면에 진공 증착법(Sputtering method)을 이용하여 (1) $\mathrm{Au}$ (Sputtered $\mathrm{Au} ; 200 \mathrm{~nm}$ 두께), (2) $\mathrm{Cr} / \mathrm{Au}$ (Sputtered $\mathrm{Cr}$ $(50 \mathrm{~nm}) / \mathrm{Au}(200 \mathrm{~nm}))$ 와 (3) $\mathrm{Ti} / \mathrm{Au}$ (Sputtered Ti $(50 \mathrm{~nm}) / \mathrm{Au}$ $(200 \mathrm{~nm}))$ 전극들을 각각 형성하였다. 진공 증착 공정에서 기판의 온도는 상온이었다. 그리고 $\mathrm{Ag}$ 전극의 경우는 $\mathrm{Ag}$ 페이스트를 압전 단결정 표면에 스크린 프린팅한 후에 $700^{\circ} \mathrm{C}$ 에서 10 분 동안 열처리하여 $\mathrm{Ag}$ (Fired $\mathrm{Ag}(5 \mu \mathrm{m})$ ) 전극을 형성하였다. 제조된 압전 PMN-PZT 단결정의 유전 및 압전 특성은 IEEE 표준 ${ }^{10,11)}$ 에 따라서 측정되었다. 전극 의 종류에 따라서 유전 상수 $\left(\mathrm{K}_{3}{ }^{\mathrm{T}}\right)$, 유전 손실 $(\tan \delta)$, 상전이 온도들 $\left(\mathrm{T}_{\mathrm{C}}\right.$ 와 $\left.\mathrm{T}_{\mathrm{RT}}\right)$, 항전계 $\left(\mathrm{E}_{\mathrm{C}}\right)$ 와 잔류 분극 등과 같은 유전 및 압전 특성에 미치는 전극의 효과를 연구하였다. 


\section{3. 결과 및 고찰}

\section{1. 고상 단결정 성장법을 이용한 압전 단결정 제조}

Fig. 1은 고상 단결정 성장법으로 제조된 세 종류의 PMN-PZT 단결정들을 보여 준다. $\mathrm{Ba}\left(\mathrm{Zr}_{0.1} \mathrm{Ti}_{0.9}\right) \mathrm{O}_{3}$ 종자 단 결정으로부터 PMN-PZT 다결정 세라믹내부에서 PMNPZT 단결정이 연속적으로 성장하였다. 열처리 공정 후에 는 PMN-PZT 다결정체 안에서 $15 \times 15 \times 5 \mathrm{~mm}^{3}$ 크기 이 상의 PMN-PZT 단결정이 제조되었다. 고상 단결정 성장 법에서는 단결정 성장은 PMN-PZT 상의 용융(melting) 온 도 이하에서 일어나기 때문에, 성장한 PMN-PZT 단결정 주위의 다결정체 PMN-PZT 세라믹스의 형상이 유지가 되 었다. 그리고 단결정 성장 열처리 공정 후에도 제조된 PMN-PZT 단결정과 다결정체에서는 조성 구배가 관찰되 지 않았으며 화학적으로 균일하였다.

\section{2. 전극 처리된 압전 단결정들}

Fig. 2는 고상 단결정 성장법으로 제조된 PMN-PZT 단 결정(Fig. 1)을 절단하여 제조된 유전 및 압전 물성 측정 용 시편의 사진이다. PMN-PZT 단결정의 유전 및 압전 특성을 평가하기 위해서, Fig. 2와 같이 판상형(두께 모드 측정용 시편 $\left.\left[4 \times 4 \times 0.5(\mathrm{t}) \mathrm{m}^{3}\right]\right)(001)$ 단결정 시편들을 각

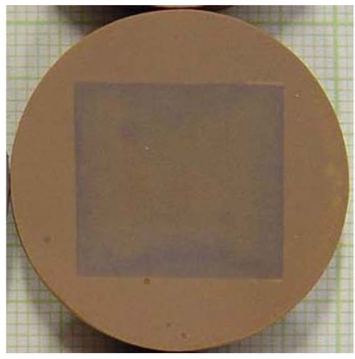

(a) PMN-PZT-A Single Crystals

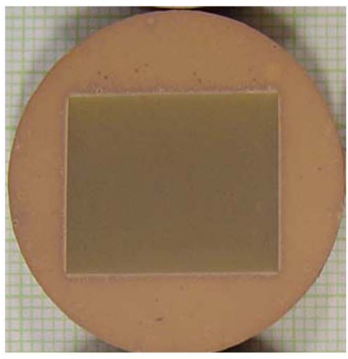

(b) PMN-PZT-B Single Crystals (piezoelectrically soft type; $T_{R T} \sim 145^{\circ} \mathrm{C}$ )

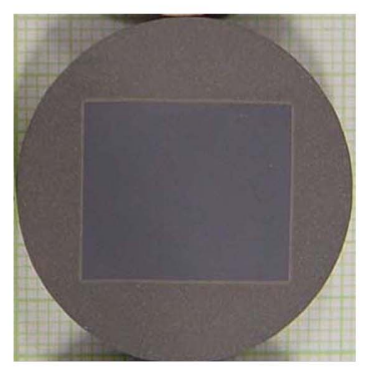

(c) PMN-PZT-C Single Crystals (piezoelectrically hard type; $\mathrm{Q}_{m} \sim 1,000$ )

Fig. 1. Three different types of (001) PMN-PZT single crystals grown by the solid-state single crystal growth (SSCG) method.

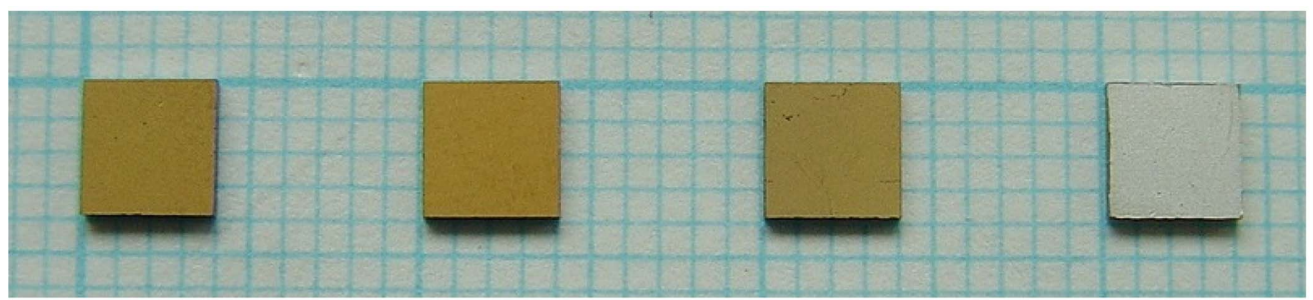

(a) PMN-PZT-A Single Crystals (piezoelectrically soft type; $K_{3}{ }^{\top} \sim 10,000$ )

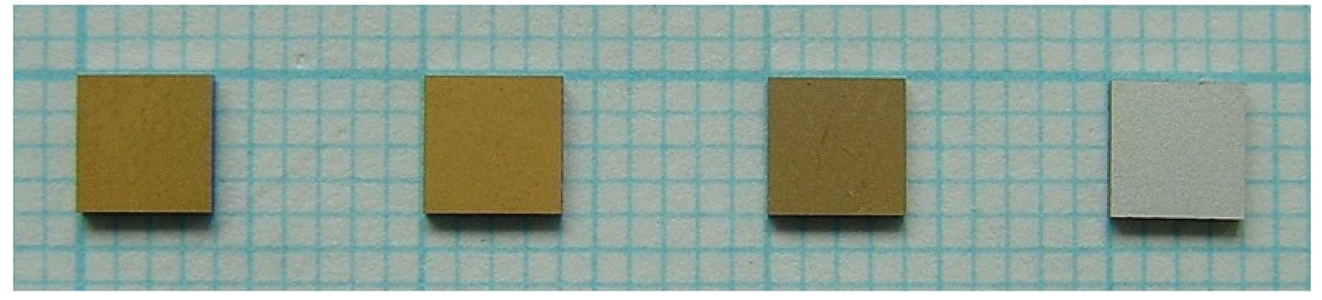

(b) PMN-PZT-B Single Crystals (piezoelectrically soft type; $T_{R T} \sim 145^{\circ} \mathrm{C}$ )

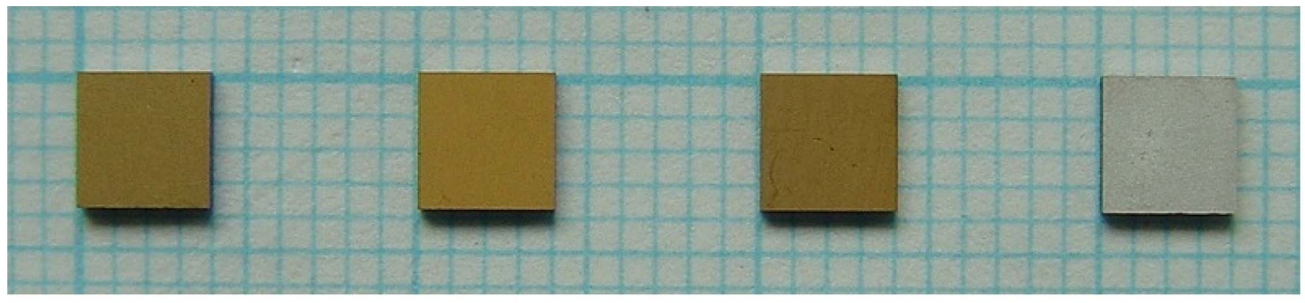

(c) PMN-PZT-C Single Crystals (piezoelectrically hard type; $\mathrm{Q}_{\mathrm{m}} \sim 1,000$ )

Fig. 2. (001) piezoelectric PMN-PZT single crystal plates with an electrode of sputtered $\mathrm{Au}$, sputtered $\mathrm{Cr} / \mathrm{Au}$, sputtered Ti/Au, and fired $\mathrm{Ag}$ electrode (from left to right). 
각 제조하였다. 그리고 (1) 진공 증착된 $\mathrm{Au}$ (Sputtered $\mathrm{Au}$ ), (2) 진공 증착된 $\mathrm{Cr} / \mathrm{Au}(\mathrm{Sputtered} \mathrm{Cr} / \mathrm{Au})$, (3) 진공 증착된 $\mathrm{Ti} / \mathrm{Au}$ (Sputtered Ti/Au)와 (4) 스크린 프린팅된 $\mathrm{Ag}$ (Fired $\mathrm{Ag}$ )의 네 종류의 전극을 각각 형성하여, 전극 의 종류에 따른 압전 단결정의 물성 변화를 관찰하였다.

\section{3. 각 전극에 따른 압전 단결정의 분극 특성}

Fig. 3은 판상형 (001) PMN-PZT 단결정들(Fig. 2)을 이 용하여, 전기장 변화에 따른 분극 특성(Polarization)의 변 화를 관찰하였다. 각 단결정들에서 (1) 진공 증착된 $\mathrm{Au}$ (Sputtered $\mathrm{Au}$ ), (2) 진공 증착된 $\mathrm{Cr} / \mathrm{Au}$ (Sputtered $\mathrm{Cr} /$ $\mathrm{Au}$ ), (3) 진공 증착된 $\mathrm{Ti} / \mathrm{Au}$ (Sputtered $\mathrm{Ti} / \mathrm{Au}$ )와 (4) 스크 린 프린팅된 $\mathrm{Ag}$ (Fired $\mathrm{Ag}$ )의 네 종류의 전극을 각각 형 성하여, 전극의 종류에 따른 분극과 항전계 $\left(\mathrm{E}_{\mathrm{C}}\right)$ 의 변화를 관찰하였다.

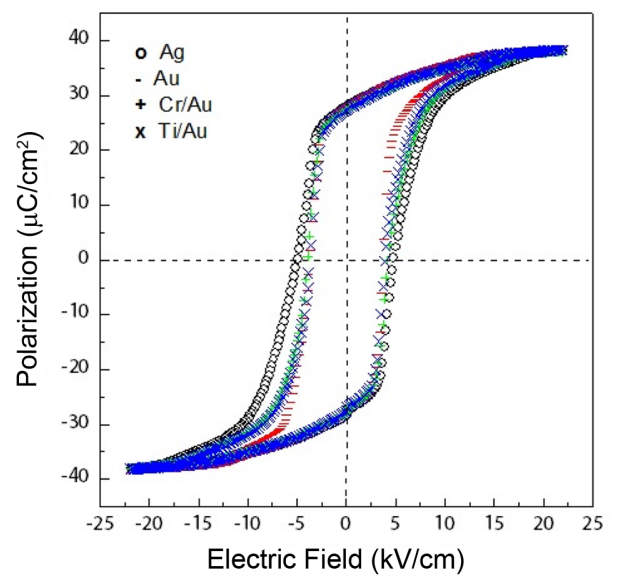

(a) PMN-PZT-A Single Crystals (piezoelectrically soft type; $K_{3}{ }^{\top} \sim 10,000$ )
Table 3에서 각 단결정들에서 전극의 종류에 따른 잔류 분극(Remanent polarization, $\operatorname{Pr}\left[\mu \mathrm{C} / \mathrm{cm}^{2}\right]$ )과 항전계(Coercive electric field, $\left.\mathrm{E}_{\mathrm{C}}\right)$ 의 크기를 표시하였다. 사용한 전극들 중 에서 $\mathrm{Ti} / \mathrm{Au}$ 전극을 사용한 경우 항전계 $\left(\mathrm{E}_{\mathrm{C}}\right)$ 는 가장 낮게 관찰되었고, $\mathrm{Ag}$ 전극을 사용한 경우는 다른 전극들에 비 하여 항전계 $\left(\mathrm{E}_{\mathrm{C}}\right)$ 가 가장 크게 관찰되었다. 이러한 전극의 종류에 따른 항전계의 차이는 높은 상전이 온도 $\left(\mathrm{T}_{\mathrm{RT}}\right)$ 를 가지는 하드 계열 PMN-PZT 단결정에서 가장 크게 나타 났다.

\section{5. 각 전극에 따른 압전 단결정의 온도에 따른 유전 및 압 전 특성 변화}

Fig. 4는 판상형 (001) PMN-PZT 단결정들(Fig. 2)을 이 용하여, 온도 변화에 따른 유전 상수의 변화를 관찰하였 다. 각 단결정들에서 (1) 진공 증착된 $\mathrm{Au}$ (Sputtered $\mathrm{Au}$ ),

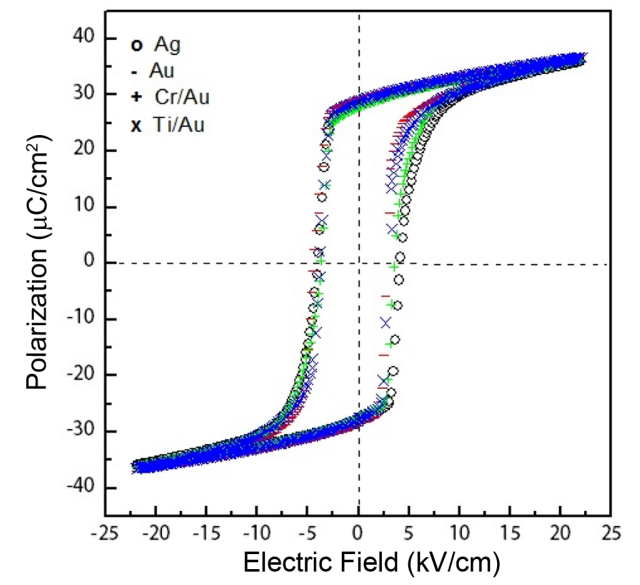

(b) PMN-PZT-B Single Crystals (piezoelectrically soft type; $\mathrm{T}_{\mathrm{RT}} \sim 145^{\circ} \mathrm{C}$ )

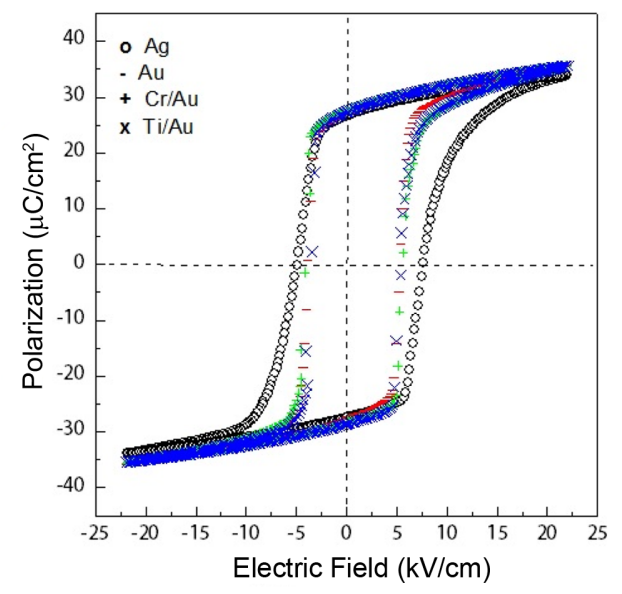

(c) PMN-PZT-C Single Crystals

(piezoelectrically hard type; $Q_{m} \sim 1,000$ )

Fig. 3. Polarization of (001) PMN-PZT single crystals $\left[4 \times 4 \times 0.5\right.$ (t) $\mathrm{mm}^{3}$; with an electrode of sputtered $\mathrm{Au}$, sputtered $\mathrm{Cr} / \mathrm{Au}$, sputtered Ti/Au, and fired Ag electrode] with electric field. 
(2) 진공 증착된 $\mathrm{Cr} / \mathrm{Au}$ (Sputtered $\mathrm{Cr} / \mathrm{Au}$ ), (3) 진공 증착 된 $\mathrm{Ti} / \mathrm{Au}$ (Sputtered $\mathrm{Ti} / \mathrm{Au}$ )와 (4) 스크린 프린팅된 $\mathrm{Ag}$ (Fired $\mathrm{Ag}$ )의 네 종류의 전극을 각각 형성하여, 전극의 종 류에 따른 상전이 온도(phase transition temperatures from rhombohedral to tetragonal phase $\left(\mathrm{T}_{\mathrm{RT}}\right)$ and from tetragonal to cubic phase $\left.\left(\mathrm{T}_{\mathrm{C}}\right)\right)$ 의 변화를 관찰하였다.
Table 3에서 각 단결정들에서 전극의 종류에 따른 상전 이 온도를 표시하였다. Table 3과 Fig. 4에서 보는 것과 같이, 세 종류의 단결정에서 모두 사용한 전극의 종류에 따라서 상전이 온도의 변화는 관찰되지 않았다. 따라서 압전 단결정의 상전이 온도와 전극의 종류와는 크게 상 관관계가 없었다.

Table 3. Remanent Polarization $\left(\mathrm{P}_{\mathrm{r}}\right)$, Coercive Electric Field $\left(\mathrm{E}_{\mathrm{C}}\right)$, Dielectric Constant $\left(\mathrm{K}_{3}{ }^{\mathrm{T}}\right)$, Piezoelectric Constant $\left(\mathrm{d}_{33}\right)$, Dielectric Loss $(\tan \delta)$, and Phase Transition Temperatures from Rhombohedral to Tetragonal Phase $\left(\mathrm{T}_{\mathrm{RT}}\right)$ and from Tetragonal to Cubic Phase $\left(\mathrm{T}_{\mathrm{C}}\right)$ of $(001)$ PMN-PZT Single Crystals $\left[4 \times 4 \times 0.5(\mathrm{t}) \mathrm{mm}^{3}\right.$; with an Electrode of Sputtered Au, Sputtered Cr/Au, Sputtered Ti/Au, and Fired Ag Electrode] at Room Temperature

\begin{tabular}{|c|c|c|c|c|c|c|c|c|}
\hline & Electrode & $\mathrm{P}_{\mathrm{r}}\left(\mu \mathrm{C} / \mathrm{cm}^{2}\right)$ & $\mathrm{E}_{\mathrm{C}}(\mathrm{kV} / \mathrm{cm})$ & $\mathrm{K}_{3}{ }^{\mathrm{T}}$ & $\tan \delta$ & $\mathrm{d}_{33}(\mathrm{pC} / \mathrm{N})$ & $\mathrm{T}_{\mathrm{RT}}\left({ }^{\circ} \mathrm{C}\right)$ & $\mathrm{T}_{\mathrm{C}}\left({ }^{\circ} \mathrm{C}\right)$ \\
\hline \multirow{4}{*}{$\begin{array}{l}\text { PMN- } \\
\text { PZT-A }\end{array}$} & $\mathrm{Au}$ & 28.2 & 3.8 & 9,460 & 0.006 & 2,330 & 73 & 132 \\
\hline & $\mathrm{Cr} / \mathrm{Au}$ & 27.6 & 4.1 & 9,500 & 0.007 & 2,650 & 72 & 131 \\
\hline & $\mathrm{Ti} / \mathrm{Au}$ & 27.5 & 3.8 & 10,350 & 0.007 & 3,000 & 71 & 131 \\
\hline & $\mathrm{Ag}$ & 28.1 & 4.8 & 8,450 & 0.007 & 2,260 & 72 & 133 \\
\hline \multirow{4}{*}{$\begin{array}{l}\text { PMN- } \\
\text { PZT-B }\end{array}$} & $\mathrm{Au}$ & 29.2 & 3.7 & 4,150 & 0.004 & 1,400 & 144 & 205 \\
\hline & $\mathrm{Cr} / \mathrm{Au}$ & 27.7 & 3.7 & 4,130 & 0.004 & 1,350 & 144 & 204 \\
\hline & $\mathrm{Ti} / \mathrm{Au}$ & 28.4 & 3.5 & 4,310 & 0.005 & 1,450 & 145 & 206 \\
\hline & $\mathrm{Ag}$ & 28.1 & 4.1 & 3,950 & 0.004 & 1,310 & 144 & 207 \\
\hline \multirow{4}{*}{$\begin{array}{l}\text { PMN- } \\
\text { PZT-C }\end{array}$} & $\mathrm{Au}$ & 27.2 & 4.6 & 3,400 & 0.002 & 1,250 & 141 & 205 \\
\hline & $\mathrm{Cr} / \mathrm{Au}$ & 28.0 & 4.8 & 3,200 & 0.002 & 1,150 & 145 & 205 \\
\hline & $\mathrm{Ti} / \mathrm{Au}$ & 28.0 & 4.5 & 3,600 & 0.002 & 1,300 & 145 & 204 \\
\hline & $\mathrm{Ag}$ & 27.1 & 6.3 & 3,150 & 0.002 & 1,100 & 145 & 206 \\
\hline
\end{tabular}

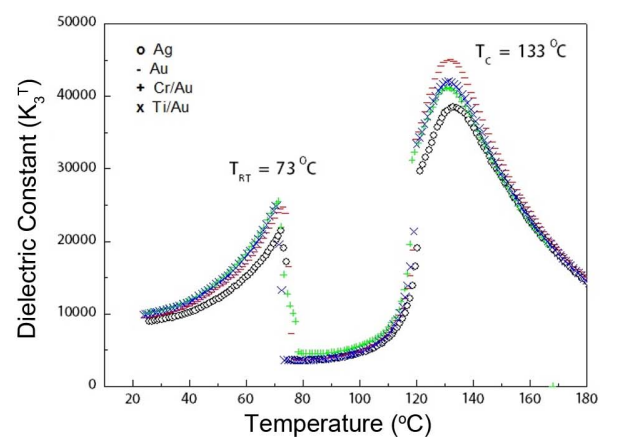

(a) PMN-PZT-A Single Crystals (piezoelectrically soft type; $\mathrm{K}_{3}^{\top} \sim 10,000$ )

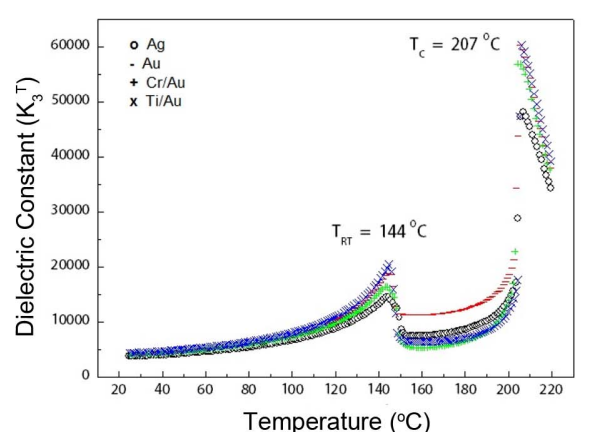

(b) PMN-PZT-B Single Crystals (piezoelectrically soft type; $T_{R T} \sim 145^{\circ} \mathrm{C}$ )

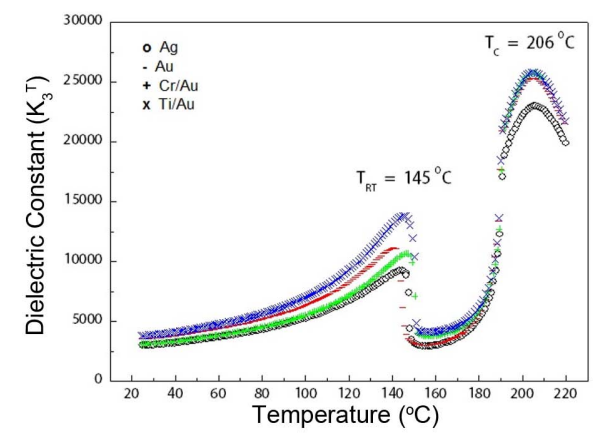

(c) PMN-PZT-C Single Crystals (piezoelectrically hard type; $\mathrm{Q}_{m} \sim 1,000$ )

Fig. 4. Dielectric constants of (001) PMN-PZT single crystals $\left(4 \times 4 \times 0.5(\mathrm{t}) \mathrm{mm}^{3}\right.$; with an electrode of sputtered Au, sputtered Cr/ $\mathrm{Au}$, sputtered $\mathrm{Ti} / \mathrm{Au}$, and fired $\mathrm{Ag}$ electrode) with temperature. 


\section{4. 각 전극에 따른 압전 단결정의 유전 및 압전 특성}

각 단결정들에서 (1) 진공 증착된 $\mathrm{Au}$ (Sputtered $\mathrm{Au}$ ), (2) 진공 증착된 $\mathrm{Cr} / \mathrm{Au}$ (Sputtered $\mathrm{Cr} / \mathrm{Au}$ ), (3) 진공 증착 된 $\mathrm{Ti} / \mathrm{Au}$ (Sputtered $\mathrm{Ti} / \mathrm{Au}$ )와 (4) 스크린 프린팅된 $\mathrm{Ag}$ (Fired $\mathrm{Ag}$ )의 네 종류의 전극을 각각 형성하여, 전극의 종 류에 따른 유전 상수, 유전 손실과 압전 상수를 측정하였다.

아래의 Table 3 에서 각 단결정들에서 전극의 종류에 따 른 유전 상수, 유전 손실과 압전 상수의 크기를 표시하였 다. 사용한 전극들 중에서 $\mathrm{Ti} / \mathrm{Au}$ 전극을 사용한 경우 유 전 상수 및 압전 상수가 가장 크게 측정되었다. 그리고 $\mathrm{Ag}$ 전극을 사용한 경우는 다른 전극들에 비하여 유전상 수와 압전상수는 가장 낮은 값을 보였다. 그러나 유전 손 실의 경우는 전극의 종류에 상관없이 일정한 값들을 보 였다.

\section{4. 결 론}

다양한 특성을 가지는 PMN-PZT 단결정들[(PMN-PZT$\mathrm{A}$ (소프트 계열; 유전 상수 10,000), PMN-PZT-B (소프 트 계열; 상전이 온도 $\left(\mathrm{T}_{\mathrm{RT}}\right) \sim 145^{\circ} \mathrm{C}$ )와 PMN-PZT-C (하드 계열; 기계적 품질 계수 $\left.\left(\mathrm{Q}_{\mathrm{m}}\right) \sim 1,000\right)$ 의 유전 및 압전 특 성에 미치는 전극의 효과를 연구하였다. 먼저 각 단결정 위에 네 종류의 전극들 [(1) 진공 증착된 $\mathrm{Au}$ (Sputtered $\mathrm{Au}$ ), (2) 진공 증착된 $\mathrm{Cr} / \mathrm{Au}(\mathrm{Sputtered} \mathrm{Cr} / \mathrm{Au})$, (3) 진공 증착된 $\mathrm{Ti} / \mathrm{Au}$ (Sputtered $\mathrm{Ti} / \mathrm{Au}$ )와 (4) 스크린 프린팅된 $\mathrm{Ag}$ (Fired $\mathrm{Ag})$ ]을 각각 형성하였고, 압전 단결정의 유전 및 압전 특성을 측정하였다. 사용한 전극들 중에서 $\mathrm{Ti} / \mathrm{Au}$ 전극을 사용한 경우 유전 상수 및 압전 상수가 가장 크 게 측정되었으나, 항전계 $\left(\mathrm{E}_{\mathrm{C}}\right)$ 는 가장 낮게 관찰되었다. 그 리고 $\mathrm{Ag}$ 전극을 사용한 경우는 다른 전극들에 비하여 유 전상수와 압전상수는 가장 낮은 값을 보였으나 항전계 $\left(\mathrm{E}_{\mathrm{C}}\right)$ 가 가장 크게 관찰되었다. 이러한 효과는 높은 기계 적 품질 계수 $\left(\mathrm{Q}_{\mathrm{m}}\right)$ 를 가지는 하드 계열 PMN-PZT-C 단결 정에서 가장 크게 나타났다. 따라서 높은 유전 상수와 압 전 상수를 필요로 하는 응용 분야에서는 $\mathrm{Ti} / \mathrm{Au}$ 전극이 유 리하고, 높은 구동 전압을 사용하는 응용 분야에서는 $\mathrm{Ag}$ 전극이 유리함을 알 수 있었다. 특히, 하드 계열의 압전 단결정의 경우 $\mathrm{Ag}$ 전극이 상대적으로 높은 항전계를 유 도하여, 압전 단결정의 사용에 안정적인 것을 알 수 있었 다. 결론적으로 압전 응용 분야에 따라서 압전 단결정의
종류는 물론이고 전극의 종류도 선별하여 사용하는 것이 필요함을 보였다.

\section{REFERENCES}

1. B. Jaffe, W. R. Cook, and H. Jaffe, Piezoelectric Ceramics; pp. 135-81, Academic Press London and New York, 1997.

2. S. -E. Park and T. R. Shrout, "Ultrahigh Strain and Piezoelectric Behavior in Relaxor Based Ferroelectric Single Crystals," J. Appl. Phys., 82 1804-11 (1997).

3. S. Zhang and F. Li, "High Performance Ferroelectric Relaxor-PbTiO 3 Single Crystals: Status and Perspective," J. Appl. Phys., 111 031301-1-50 (2012).

4. S. Zhang, F. Li, X. Jiang, J. Kim, J. Luo, and X. Geng, "Advantages and Challenges of Relaxor- $\mathrm{PbTiO}_{3}$ Ferroelectric Crystals for Electroacoustic Transducers - A Review," Prog. Mater. Sci., 68 1-66 (2015).

5. N. Yamamoto, K. Itsumi, Y. Hosono, and Y. Yamashita, "Effects of Electrodes on Dielectric and Piezoelectric Properties of Lead Magnesium Niobate-Lead Titanate Single Crystal Transducer," Jpn. J. Appl. Phys., 50 09NC04-1 4 (2011).

6. H. -Y. Lee, Development of High-Performance Piezoelectric Single Crystals by Using Solid-state Single Crystal Growth (SSCG) Method; pp. 158 in Handbook of Advanced Dielectric, Ed. by Z. -G. Ye, Piezoelectric and Ferroelectric Materials, CRC Press, New York, 2008.

7. S. Zhang, S. -M. Lee, D. -H. Kim, H. -Y. Lee, and T. R. Shrout, "Elastic, Piezoelectric, and Dielectric Properties of $0.71 \mathrm{~Pb}\left(\mathrm{Mg}_{1 / 3} \mathrm{Nb}_{2 / 3}\right) \mathrm{O}_{3}-0.29 \mathrm{PbTiO}_{3}$ Crystals Obtained by Solid-State Crystal Growth," J. Am. Ceram. Soc., 91 [2] 683-86 (2008).

8. S. Zhang, S. -M. Lee, D. -H. Kim, H. -Y. Lee, and T. R. Shrout, "Temperature Dependence of the Dielectric, Piezoelectric, and Elastic Constants for $\mathrm{Pb}\left(\mathrm{Mg}_{1 / 3} \mathrm{Nb}_{2 / 3}\right) \mathrm{O}_{3}$ - $\mathrm{PbZ}$ $\mathrm{rO}_{3}-\mathrm{PbTiO}_{3}$ Piezocrystals," J. Appl. Phys., 102 114103-1 5 (2007).

9. S. Zhang, S. -M. Lee, D. -H. Kim, H. -Y. Lee, and T. R. Shrout, "Characterization of Mn-modified $\mathrm{Pb}\left(\mathrm{Mg}_{1 / 3} \mathrm{Nb}_{2}\right.$ 3) $\mathrm{O}_{3}-\mathrm{PbZrO}_{3}-\mathrm{PbTiO}_{3}$ Single Crystals for High Power Broad Bandwidth Transducers," Appl. Phys. Lett., 93 122908-1 3 (2008).

10. S. Zhang, C. Randall, and T. R. Shrout, "Characterization of Perovskite Piezoelectric Single Crystals of $0.43 \mathrm{BiScO}_{3}$ $0.57 \mathrm{PbTiO}_{3}$ with High Curie Temperature," J. Appl. Phys., 95 [8] 4291-95 (2004).

11. ANSI/IEEE Std 176-1987, IEEE Standard on Piezoelectricity, 1987. 